\author{
Universidade de Brasília \\ Centro de Excelência em Turismo
}

\title{
Proposta de um Posto de Orientação Virtual no turismo de Brasília
}

Guilherme Aurélio Gonçalves de Melo Pós-graduação: Gestão da Hospitalidade

Brasília

2004 


\author{
Universidade de Brasília \\ Centro de Excelência em Turismo
}

\title{
Proposta de um Posto de Orientação Virtual no turismo de Brasília
}

\begin{abstract}
Apresentação de monografia à Universidade de Brasília como condição prévia para a conclusão do Curso de PósGraduação "Lato Sensu" em Gestão da Hospitalidade, sob a orientação do Prof. Jorge Monteiro Fernandes.
\end{abstract}

Guilherme Aurélio Gonçalves de Melo

Brasília, Janeiro de 2004

\section{Brasília}




\section{4 \\ Agradecimento}

Agradeço aos meus colegas de Gestão de Hospitalidade por ter o privilegio em estar todos os dias das semanas convivendo e aprendendo com eles. Agradeço ao Centro de Excelência em turismo em oferecer um curso de qualidade e excelência. 


\section{Dedicatória}

Dedico a monografia para minha linda esposa Márcia Melo, aos meus dois filho Guilherme André Melo e Ana Beatriz Melo e aos meus pais, cujo apoio tenha sido fundamental para elaboração do trabalho. 


\section{Resumo}

A proposta deste trabalho é criar um Posto de Orientação Virtual - POV - que será utilizado pelos turistas de negócios tornando como um guia virtual. Serão abordadas as principais ferramentas de Gestão da Tecnologia de informação especialmente dedicada à produção de informações com característica de excelência no atendimento e de qualidade turísticas na cidade de Brasília. Serão analisadas e abordadas duas etapas de implementação. 


\section{Sumário}

Introdução ------------------------------------------------------------- 01

1. Em 2004, Brasília aposta no turismo de negócios----------------- 03

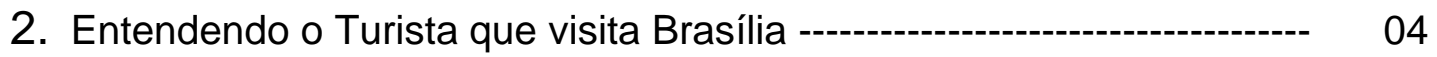

3. A necessidade de planejar e desenvolver estratégias no turismo------ 06

3.1 Saber fazer um planejamento eficaz para utilização da TI---------- 08

4. A evolução da sociedade da informação---- 09

4.1 Gestão da Tecnologia da Informação---------------------------- 10

4.2 Turismo, informação e tecnologia combinam?--------------------- 14

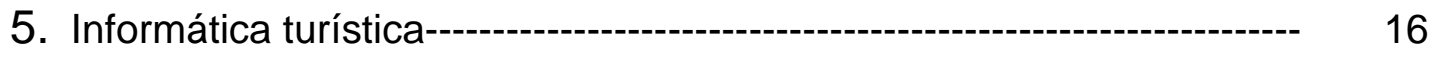

5.1 Conceito e características da informática turística------------------ 16

6. Posto de Orientação Virtual: Primeira etapa de implementação-------- 21

6.1Descrição--------------------------------------------- 21

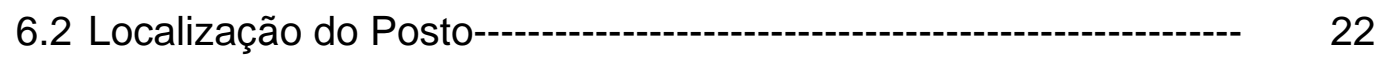

6.3 Como o turista acessará as informações?-------------------------- 24

6.4 Qual é a função do roteiro?----------------------------------- 24

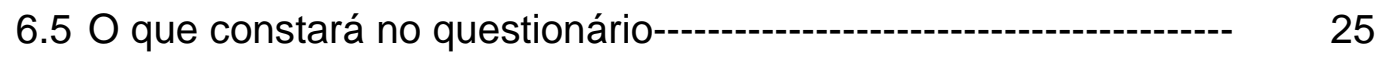

6.6 Fornecimento da senha para acessar as informações------------- $\quad 27$

6.7 O posto localizado no Hotel-----

6.8 Vantagens para o turista--- 28

7. Posto de Orientação Virtual: Segunda etapa de implementação------ 28

7.1 Como serão oferecidos os dados para o turista----------------- 29

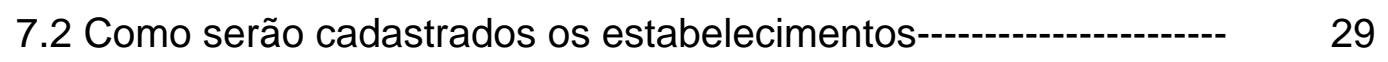

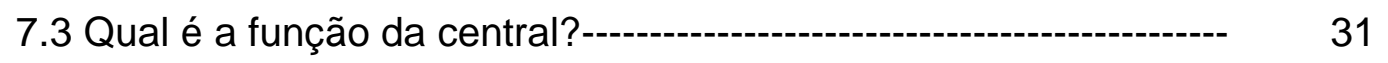

Conclusão----- 33

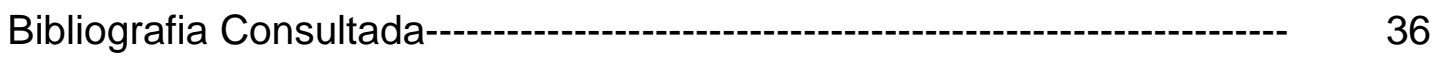





\section{Introdução:}

Atualmente, o desenvolvimento das atividades turísticas constitui preocupação comum a praticamente todas as cidades. Tais atividades existem quando há deslocamento de pessoas do seu local para outro lugar por tempo determinado e devido a motivações diversas. Para avaliar o sucesso dessa atividade, deve-se considerar alguns requisitos de hospitalidade: atrativos e/ou recursos naturais e culturais; equipamentos turísticos (meio de hospedagem, alimentação e transporte); infra-estrutura, etc.

O turismo gera desenvolvimento e pode servir de base econômica para uma região ou uma localidade. É uma atividade que consome espaço geográfico: exige a construção de infra-estrutura, utiliza-se de recursos turísticos e promove a integração da população nativa, entre outros múltiplos aspectos.

Seu desenvolvimento, porém, deve ser direcionado e controlado levando-se em consideração certas restrições ambientais, sociais, culturais e econômicas. Sem essas considerações, a atividade turística poderá crescer de maneira espontânea e desordenada, provocando impactos negativos.

Os processos de planejamento turístico exigem estudos muitas vezes longos e onerosos. A execução requer um alto investimento e, com freqüência, faltam recursos financeiros para os investimentos em ferramentas adequadas. Entre essas ferramentas encontra-se a informação, fundamental para a sustentação da tomada de decisões, facilitando a aceitação de ações e investimento na área de turismo. No entanto, observa-se que há falta de informação atualizada e de mecanismos de gestão de grandes quantidades de 
informação que permitam analisar e prever todo tipo de impacto que a atividade turística possa gerar. Com o avanço tecnológico, abrem-se perspectivas de obtenção de dados confiáveis e ordenação da informação, o que facilita o processo de desenvolvimento do turismo de maneira organizada e sustentável, por meio de sistema de informação.

A proposta do presente trabalho é desenvolver uma ferramenta específica na área da informação ao turista em Brasília. Trata-se de proposta da criação de Postos de Orientação Virtual (POV), que servirão como guia turístico virtual para os turistas que visitam Brasília a negócio.

O Posto de Orientação Virtual mostrará as facilidades em serviços em geral para turistas que vem a negócio a Brasília, oferecendo um serviço inovador e de rápido acesso à informação, em uma espécie de guia eletrônico.

O trabalho abordará duas etapas para a criação e funcionamento dos Postos de Orientação Virtual, descrevendo os processos passo a passo. Em primeiro lugar, serão analisados os aspectos referentes à própria função do POV, sua localização e vantagens principais da ferramenta. Na segunda etapa, serão examinados os meios pelos quais as informações poderão ajudar os turistas de uma forma objetiva.

Em cada uma dessas partes do trabalho, será observada uma rotina processualística tecnicamente adequada. Também serão analisadas as premissas básicas, adoção de parâmetros de qualidade via TI, assim como, atualidade, objetividade, sustentabilidade, credibilidade (técnica e ética), abrangência, consistência, grau de interação para dentro e competitividade mercadológica. 
Este trabalho é composto, enfim, de: fundamentos teóricos, experiências, conclusão e referencias bibliográfica.

\section{Em 2004, Brasília aposta no turismo de negócios:}

Texto retirado do Jornal "Correio Braziliense" no dia 25 de dezembro de 2004, tratando sobre o otimismo do turismo de negócios no Distrito Federal.

"O ano 2004 promete ser o melhor dos últimos anos para o turismo do Distrito Federal. As boas notícias se referem principalmente a um crescimento esperado para o turismo de negócios e de eventos, responsável por trazer $77 \%$ dos turistas que viajam para a cidade anualmente. Pelo menos três grandes hotéis serão inaugurados neste ano e juntos vão consumir cerca de R\$ 103 milhões em investimentos totais, segundo previsão da Associação Brasileira da Industria Hoteleira (ABIH)". (Texto Retirado no Correio Braziliense).

As expectativas de melhora já animam os empresários envolvidos no setor. Muitos comemoram o fechamento de contratos na primeira quinzena de janeiro, período em que as empresas ficaram às moscas no ano passado. "Com o governo mais estabilizado, aumenta também o volume de eventos corporativos. As empresas vêem que o governo está apto a atender às reivindicação desses congressos", afirma a presidente do Sindieventos, Elenita Valle.

O setor hoteleiro espera crescer $20 \%$ em geral. No ano passado, 47 hotéis do plano piloto movimentaram cerca de $R \$ 200$ milhões de reais. A força atrativa do Governo Federal é a grande responsável pela expectativa positiva. "Brasília ainda é uma grande caixa de repercussão. Com as eleições municipais, a cidade 
deve atrair muita gente", aposta o vice-presidente da Associação Brasileira da Industria Hoteleira do Distrito Federal (ABIH-DF), Helder Carneiro.

Os eventos se tornam essenciais para a economia do DF. Segundo a última pesquisa realizada pelo Brasília Convention \& Bureaux, o setor empregava, em 2001, 10.2 mil pessoas, além de outros 150 mil empregados indiretos. A estimativa na época era que cerca de 1,3 milhão de pessoas participavam de eventos no DF por ano. Os participantes vindo de fora da cidade gastavam, diariamente, $\mathrm{R} \$ 325 . “$

\section{Entendendo o turista que visita Brasília:}

Uma pesquisa realizada pela revista Brasília Convention \& Visitors Bureau - edição 2001 - identificou a existência de diferentes motivações para uma visita a Brasília. Foram criadas três categorias de identificação para os turistas. A primeira é o "O turista convencional" que tem a sua vinda ao DF motivada pelo desejo de conhecer ou para visitar parentes e amigos; o "turista de eventos" cuja vinda foi provocada na participação de eventos e, finalmente, o "turista de negócios" aquele que vem para reuniões, congressos e eventos políticos.

Analisando os resultados da pesquisa constatou-se que os verdadeiros turistas, chamados pela pesquisa de "turista convencional", fazem parte de uma pequena parcela com $5 \%$ apenas. Os que tem como objetivo visitar seus parentes e amigos fazem parte de uma parcela de 11\%. E que a maioria das visitas são em função de interesses profissionais, sejam eles associados a eventos (26\%), em menor escala, ou à realização de negócios (52\%), na sua maioria. 
A pesquisa classificou os turistas pela região de origem, concluindo que provêem, em sua maioria, da região Sudeste, com a seguinte distribuição:

- São Paulo (22\%);

- $\quad$ Rio de Janeiro (16\%);

- Minas Gerais (14\%).

Já o perfil sócio-demográfico do turista do DF demonstrou que a maioria dos visitantes é do sexo masculino (63\%), apresenta idade entre 30 a 55 anos, possui nível de escolaridade superior e pertence às classes sociais $A / B$, segundo a ABIPEME - Associação Brasileira de Institutos de Pesquisa de Mercado de Classificação Social.

Um ponto importante analisado nessa pesquisa e de extrema importância para este trabalho, é que as informações e orientações aos turistas são muito precárias. O espaço de informação e orientação a esses turistas em geral são preenchidos por parentes e amigos. A pesquisa revela que se esse turista não tivesse essa facilidade seu roteiro turístico no DF praticamente não existiria, pois não há nenhum incentivo local a exploração dos pontos turísticos. Realmente, os turistas entrevistados ficaram insatisfeitos com o atendimento recebido, a falta de informações, a baixa qualificação dos atendentes frentes às informações solicitadas e com as irregularidades dos horários de atendimento, todos constituindo fatores negativos da infra-estrutura que hoje existe em Brasília para atender adequadamente os seus visitantes.

A avaliação da pesquisa mostrou que o DF precisa melhorar a sua própria hospitalidade. Em termos positivos, as opiniões revelaram que Brasília tem o 
diferencial na sua arquitetura urbanística, os parques e jardins bem conservados, os conjunto de pontos turísticos "oficiais" e o trânsito que flui rápido. Já as opiniões negativas revelaram a frieza ligada a seus cidadãos, má conservação da rodoferroviária e a impessoalidade da cidade.

O momento, portanto, é oportuno para que Brasília incremente as bases para um turismo de qualidade. O ponto primordial é que Brasília seja vista como uma cidade que valoriza o turista que vem de fora. As informações turísticas devem ser claras e precisas. É necessário melhorar a infra-estrutura, fornecer ao turista o mínimo de informações seguras para sua hospedagem, seu deslocamento, seu lazer, enfim, para o turismo que ele veio realizar.

\section{A necessidade de planejar e desenvolver estratégias no turismo:}

A estratégia no turismo tornou-se uma ferramenta importantíssima para o sucesso do empreendimento turístico. O surgimento e a preservação do turismo como um setor dinâmico e não-estático dependem em grande parte da adoção de um enfoque estratégico no que diz respeito a planejamento e desenvolvimento. Por sua vez, o sucesso desse enfoque depende fundamentalmente de uma analise sistemática e estruturada dos amplos fatores ambientais que afetam a demanda do turismo como parte essencial do processo de planejamento.

Estamos diante de um mundo que, de uma forma caleidoscópica, muda diante de nossos olhos. Talvez fosse correto afirmar que estamos mergulhados neste mundo, completamente envolvidos em um processo de mudança para o qual nossa sociedade parece não ter se preparado adequadamente. 
A necessidade de se planejar estratégias nos dia hoje se tornou algo extremamente importante. Principalmente no turismo. Empreendimento que não visa o planejamento de estratégias corre o risco de perder mercado e até fechar. Cada vez que um empreendimento investe na tecnologia de informação, aumenta sua viabilidade de sucesso. Está fora da moda empresário que insiste em não gastar verbas para a implementação da tecnologia da informação. Isto ocorre freqüentemente, pois o empreendedor não é orientado e não sabe como esse processo pode ajudar a sua empresa.

A tecnologia de informação tornou-se algo muito importante na elaboração de estratégias. Um empreendimento que utiliza as principais ferramentas de TI terá vantagens competitivas em relação ao empreendimento que ainda não utiliza. Isso fica claro num conceito teórico. A utilização da TI facilita em muito a vida dos turistas e, sobretudo do empreendimento. Para o empreendedor de atividade turística, os dados coletados do cliente em potencial que visita a cidade de Brasília ajudarão a elaborar estratégia para suprir as devidas necessidades de cada cliente. Já para o turista a TI tem um papel fundamental, pois poderá fornecer-Ihe rapidez de informações; as informações de seu interesse; contatos diretos com estabelecimentos turísticos e também tornando-se um orientador preciso para captar informação. Para ambos a TI é importante. A necessidade de planejar e desenvolver estratégias de TI no turismo provoca mudança importantíssima para sucesso do estabelecimento turístico.

Realmente, a precariedade de informação turística existente em Brasília é algo muito preocupante. A pesquisa realizada pelo Brasília Convention \& Visitors Bureau revela que os turistas que visitam Brasília ficam frustrados com a 
qualidade precária da informação. A TI entra como um "doutor do turismo" que fiscaliza e orienta a formulação de estratégia para que os turistas não saiam insatisfeitos em relação à informação e serviços em Brasília. Este título de "Doutor" para TI é a ferramenta para sobrevivência de um estabelecimento turístico.

\subsection{Saber fazer um planejamento eficaz para utilização da TI.}

No empreendimento turístico é necessário planejar antes de implantar um sistema de informação. Sobretudo para saber a finalidade da implantação. As vantagens são muitas, pois um estabelecimento turístico que utiliza a TI como uma ferramenta se sobressai em termos de qualidade, objetividade, segurança, confiabilidade, sustentabilidade (financeira e técnica), credibilidade (técnica e ética) e consistência.

O planejamento dá oportunidade para entender com profundidade os tipos de turistas que visitam Brasília, entender o gosto desses turistas e quais os seus interesses em visitar a cidade: se é turismo de negocio ou turismo convencional. Depois de coletados e analisados esses dados através de uma pesquisa de mercado é possível identificar os diferentes tipos de turistas que visitam Brasília mais freqüentemente. 


\section{A evolução da sociedade da informação:}

Alvin Toffler identificou três fases, que podemos definir como saltos tecnológicos no decorrer dos tempos, que revolucionaram e continuarão a revolucionar nossa sociedade. A primeira onda é a chamada agrícola; a segunda, a industrial e a terceira, a onda do sistema de informação. Cada uma delas evoluiu paralelamente, coexistindo entre si. Atualmente, estamos sob efeito da ultima: a onda dos sistemas de informação.

No âmbito dos computadores pessoais, a onda dos sistemas de informação tornou-se forte, poderosa e sua evolução tem sido cada vez maior, provocando verdadeiros choques nas empresas e na computação de maneira geral.

Nas décadas de 60 e 70, as empresas utilizavam máquinas de grande porte, os chamados mainframes, que possuíam alta capacidade de processamento de um grande volume de dados, porém ofereciam poucos recursos gráficos, interativos e de aproximação do usuário com a máquina.

No início da década de 80 , os computadores pessoais assumiram a frente; com a utilização de micros em um sistema chamado 'stand alone', no qual a máquina tinha um processador totalmente dedicado ao seu usuário. Surgiram os processadores de texto, as planilhas eletrônicas e os bancos de dados.

Emergiu a necessidade do multiprocessamento, através de conexão de vários PCs. Criaram-se as chamadas redes de microcomputadores.

A filosofia da conectividade entre diversos fabricantes tornou as redes de computadores corporativas. As empresas puderam, então, agilizar sua produção, descentralizando as informações e podendo recuperá-las de modo rápido. 
Conseqüentemente, os níveis hierárquicos nas empresas diminuíram, com forte tendência a horizontalização. Hoje, vemos empresas com unidades de negocio, autônomas, que, em especial na área de informática

\subsection{Gestão da Tecnologia da informação:}

"A informação tecnológica pode ser a maior ferramenta dos tempos modernos, mas é o julgamento de negócios dos humanos que a faz poderosa" Charles B. Wang.

O ambiente empresarial está mudando continuamente, tornando-se mais complexo e menos previsível, e cada vez mais dependentes de informação e de toda a infra-estrutura tecnológica que permite o gerenciamento de enormes quantidades de dados. A tecnologia está gerando grandes transformações, que estão ocorrendo a nossa volta de forma ágil e sutil. É uma variação com conseqüências fundamentais para o mundo empresarial, causando preocupação diária aos empresários e executivos das corporações, com o estágio do desenvolvimento tecnológico das empresas e/ou de seus processos internos. A convergência desta infra-estrutura tecnológica com as telecomunicações que aniquilou as distâncias está determinando um novo perfil de produtos e de serviços.

Segundo Adriana Beal, "O principal benefício que a tecnologia da informação traz para as organizações é a sua capacidade de melhorar a qualidade e a disponibilidade de informações e conhecimentos importantes para a empresa, 
seus clientes e fornecedores. Os sistemas de informação mais modernos oferecem às empresas oportunidades sem precedentes para a melhoria dos processos internos e dos serviços prestados ao consumidor final".

Ao ler um estudo de caso sobre as mudanças tecnológicas ocorridas na Água de Cheiro, me deparei com o seguinte comentário de um dos diretores: "A tecnologia traz a necessidade de mudança cultural e passa a exigir das pessoas a capacidade de reciclar seus conceitos e seus paradigmas. As pessoas não precisam mais saber gerar informação, pois a sua geração é automática. Precisam sim, saber usar a informação. Caso a empresa não tenha tempo nem recursos para investir em treinamento, torna-se necessário fazer uma reciclagem de quadro. "Tenta-se mudar as pessoas, mas, se precisar, muda-se de pessoas"."

Este exemplo clarifica bem, como este novo cenário está afetando interesses, valores e rotinas há muito tempo cristalizado em pessoas, eliminando tarefas, gerando desemprego, e exigindo aperfeiçoamento contínuo.

Na Água de Cheiro, eles reconhecem a importância crescente da TI e da rapidez como esta vem provocando mudanças de comportamento das sociedades. No entanto, admitem algumas limitações ao seu uso, dado a especificidade do seu negócio.

Cabe aqui uma consideração de Jacques Marcovith, "que quando se impõe limites à TI sem prévio estudo, caracteriza-se uma nociva desconsideração de tendências, onde a competição não estaria acontecendo apenas entre empresas, mas entre padrões ou comportamentos pouco convencionais". Cabe a cada 
organização encontrar uma abordagem adequada às suas necessidades específicas em gestão da informação.

Outro esclarecimento fundamental, é que A TI e seus computadores não possuem "poderes mágicos" de resolver problemas de gestão, racionalizar processos ou aumentar a produtividade. Bill Gates em seu livro: A Estrada do Futuro fez o seguinte comentário: "Diretores de empresas pequenas e grandes ficarão deslumbrados com as facilidades que a tecnologia da informação pode oferecer. Antes de investir, eles devem ter em mente que o computador é apenas um instrumento para ajudar a resolver problemas identificados. Ele não é, como às vezes as pessoas parecem esperar, uma mágica panacéia universal. Se ouço um dono de empresas dizer: "Estou perdendo dinheiro, é melhor comprar um computador", digo-lhe para repensar sua estratégia antes de investir. A tecnologia, na melhor das hipóteses, irá adiar a necessidade de mudanças mais fundamentais. A primeira regra de qualquer tecnologia utilizada nos negócios é que a automação aplicada a uma operação eficiente aumenta a eficiência. A segunda é que a automação aplicada a uma operação ineficiente aumenta a ineficiência."

Atualmente a gestão estratégica da informação tornou-se uma parte crítica e integrada a qualquer estrutura gerencial de sucesso.

O uso da reengenharia de processos para direcionar os novos sistemas de informação pode proporcionar um aumento significativo da satisfação dos clientes, 
e/ou a redução de custos, ao contrário das iniciativas que envolvem o uso de tecnologia apenas para fazer mais rápido o mesmo trabalho.

É complicado tentar explicar que a análise de aquisição dos produtos e serviços de tecnologia está vinculada à avaliação dos valores internos da empresa, desde a sua cultura, o nível dos seus gestores e colaboradores, até a análise dos seus negócios, sem desconsiderar o planejamento estratégico para o futuro. É imprescindível esta reflexão interna.

O novo desafio dos gestores de TI está no alcance de metas e objetivos organizacionais específicos, ao invés de satisfazer requisitos de usuário muitas vezes não relacionados aos objetivos organizacionais, passando a ser um profissional que fale em clientes, concorrência global e retorno sobre investimento, perdendo a fixação do diálogo em apenas plataformas, computação cliente/servidor e orientação a objetos e outras mais, combinando ainda habilidades de liderança e comunicação com conhecimentos técnicos e do negócio, capaz de exercer um papel decisivo em todas as questões de gestão da informação e de aprimoramento dos processos organizacionais.

Concluindo, a Tecnologia da Informação está permeando a cadeia de valor, em cada um de seus pontos, transformando a maneira como as atividades são executadas e a natureza das interligações entre elas. Está, também, afetando o escopo competitivo e reformulando a maneira como os produtos e serviços atendem às necessidades dos clientes. Estes efeitos básicos explicam porque a Tecnologia da Informação adquiriu um significado estratégico e diferencia-se de 
muitas outras tecnologias utilizadas nos negócios. Aos administradores cabe o alerta do Charles Wang, "que a TI mudou tudo que você aprendeu sobre gestão, e está achatando milhões de administradores que deixaram de conformar-se ao inevitável. Infelizmente forças assim, não abrem exceções, nem mesmo para você, talvez principalmente para você".

\subsection{Turismo, informação e tecnologia combinam?}

Que o Brasil tem um imenso potencial turístico, ninguém dúvida. Mas do que vale este imenso potencial, se está mal aproveitado? Em tempos de globalização, competitividade e agilidade, o turismo brasileiro não pode estar alheio às evoluções tecnológicas e de gestão de informação.

O potencial turístico brasileiro pode ser vislumbrado apenas de ponto de vista de sua geografia. Dos 26 estados, 17 são litorâneos, somando 7.400 km de litoral dotado em sua maior parte de areia brancas e banhado por águas cristalinas. Abrigam também grandes florestas, parques ecológicos, reservas biológicas além do patrimônio histórico e cultural. O clima é predominantemente tropical e, acima do Rio de Janeiro, é possível freqüentar as praias praticamente todos os meses do ano.

O turismo brasileiro tem problema de ordem estrutural, social, cultural e econômica e seu crescimento é considerado tímido, mesmo com os grandes investimentos que estão sendo feitos por nacionais e internacionais e pelo poder publico. Exemplos desses investimentos são: o complexo turístico da Costa do Sauípe, na Bahia e a verba do governo federal de cerca US\$ 670 milhões destinadas entre 1995 e 1999, para construção de aeroporto, saneamento básico 
e preservação histórica ambiental. E entre 2000 e 2003, os valores são da ordem de US\$1,7 bilhão, segundo o Instituto Brasileiro de Turismo - EMBRATUR.

A informação na agência de turismo é preponderante, pois seu negócio não se resume apenas em vender viagens, passagens, hospedagem ou pacotes turísticos, e sim divulgar a informação, que antes deve ter sido coletada e devidamente tratada. Para que um pacote de viagens seja vendido é necessário fazer o cliente construir sonho, imaginar seu destino isto é difícil apenas através de catálogos e fotos. É necessário interatividade, agilidade e quem sabe até realidade virtual e isso as tecnologias podem oferecer.

O turismo precisa ser ainda mais profissional, necessitando, portanto, de planejamento, desenvolvimento de estratégias, especialização de mão de obra e qualidade na prestação de serviços, utilizando-se de tecnologias e gestão da informação para superar as expectativas dos clientes. 


\section{Informática Turística:}

\subsection{Conceitos e características da informática turística:}

A informática é a ciência que permite processar eletronicamente uma informação dos dados armazenados na memória de um computador e seguindo as instruções de um programa.

Dessa forma, a informática aplicada ao setor turístico trata de concepção, realização e utilização dos sistemas que processam informação relacionada com a gestão. Tais como as reservas, vendas, contabilidades, bancos de dados, etc.

Portanto, o conjunto de teoria e técnicas postas em jogo para o tratamento automático das informações com a ajuda de meios de cálculos eletrônicos aplicados ao setor de transporte, hotelaria e restauração, agência de viagens e escritórios e centros de informação turísticas.

O tratamento da informação move-se em dois níveis:

a. A informática do tratamento de textos e dos bancos de dados aplicada à informação dos serviços turísticos.

b. A informática de gestão que trata da gestão comerciais, industriais, financeiros, analise de sistemas de gestão e gestões administrativas.

Um computador eletrônico é uma máquina que, em muitos aspectos, funciona de forma similar ao cérebro de um ser humano que quer resolver um problema. Como funciona um Computador?

Em primeiro lugar, o computador recebe a informação que chega do exterior por meio de uma unidade de entrada. Uma vez recebida a ordem, esta 
passa para a memória do computador, na qual se encontram armazenados dados e instruções de operação que permitirão à maquina resolver o problema. Conectada à memória encontra-se, no computador, a unidades de processamento central, que é formada por dois importantes blocos: a unidade de controle e a unidades aritmético-lógica. A primeira delas tem como função extrair da memória as instruções necessárias para resolver o problema e as seqüências com que devem ser executadas, transferindo essa seqüência para a unidade aritméticológica que, uma vez recebida, extrai da memória os dados necessários e executa todas as operações previstas.

Realizado todo processo, o resultado obtido passa para a memória, onde fica armazenado até que, em determinado momento, é retirado dela por meio de uma unidade de saída que é encarregada de proporcionar a solução procurada.

O tratamento da informação segue, portanto, o processo:

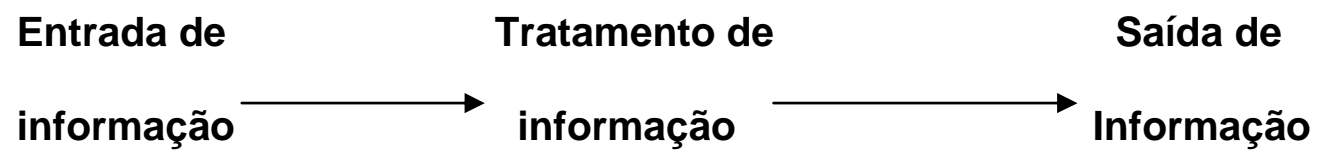

O processo de tratamento da informação passa pelas seguintes fases com uma decodificação de linguagens para que sejam entendidas pela máquina e pelo homem.

a) Coletas de dados (por exemplo: serviços da fatura do hotel por meio dos vales e das comandas).

b) Leitura dos dados.

c) Tratamento dos dados (por exemplo: elaboração da fatura do cliente).

d) Saída de dados (por exemplo: fatura confeccionada e impressa). 
O processo de tratamento de dados tem o seguinte esquema no computador:

1) Unidade de entrada. É o sistema mediante o qual são introduzidos no computador os dados e as instruções que formam o programa que deverá se executado. Podem ser de vários tipos: teclados com telas, leitora de fichas perfuradas, discos, etc. Contudo, seja qual for o sistema, sempre é o instrumento de comunicação entre o homem e a máquina.

2) Memória. É a parte do computador na qual são introduzidos dados e instruções que formam o programa, seqüência de instruções que detalha passo a passo como se deve fazer uma tarefa. Dela, a unidade de processamento central extrai os elementos que necessita para executar o programa. Uma vez finalizado, ficam armazenados na memória os resultados que são extraídos pela unidade de saída.

3) Unidades de processamento central. É o "coração" do computador. Sua missão consiste em interpretar e executar todas as instruções contidas no programa. Por sua vez, é composta por dois elementos bem diferenciados. A unidade aritmético-lógica e a unidade de controle.

- Unidade Aritmético-lógica. Através dela é realizado todos os cálculos e comparações (decisões) que formam o programa. Durante toda a elaboração deste, fluem entre essa unidade e a 
memória os diferentes dados indicando para a unidade de controle o tipo de operação a ser realizada com esses dados.

- Unidade de controle. Ela está encarregada de interpretar e selecionar as diferentes instruções que formam o programa e que se encontram armazenadas na memória, aqueles que significam instruções interpreta e gera os sinais que envia para as outras unidades da máquina que são encarregadas de executa-las.

4) Unidade de Saída. A unidade de saída é um dispositivo similar à unidade de entrada, já que também serve de comunicação entre o homem e a máquina. Obtém na memória a informação codificada e conserte em um formato que, ou pode ser diretamente interpretado pelo homem, ou transferido para outra máquina de processamento, como discos ou fitas magnéticas.

Esquematicamente, a estrutura do computador é a seguinte:

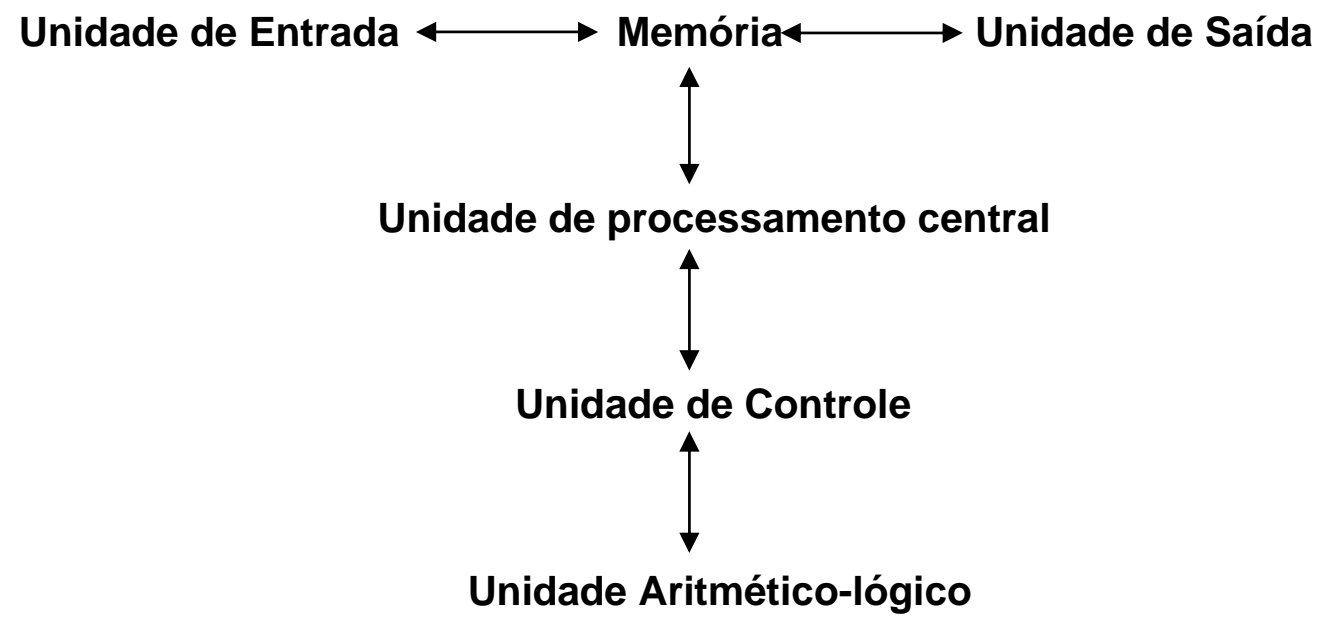

Para realizar todos os processos informativos, o computador necessita de alguns suportes: 
a) Hardware: os circuitos e redes que o computador possui com base em aspectos físicos: discos,"compact disc" (CD-ROM), arquivos, fitas magnéticas, teclados. Os arquivos são três tipos:

1. Arquivos permanentes, intergrados por um conjunto de informações relativas à informação constante, de situação ou histórica.

2. Arquivos de movimento que contêm informação que serve para atualizar um arquivo permanente.

3. Arquivos de manobra que contêm informação armazenada para resultados intermédios e que serão utilizados mais tarde no mesmo processo.

b) Software: os programas escritos para o computador que podem ser de diversas formas: tratamentos de textos, bancos de dados, gestão administrativas, etc. 


\section{Posto de Orientação Virtual: Primeira etapa de implementação}

\subsection{Descrição:}

Nesta parte serão explicadas a principal função do Posto de Orientação Virtual e forma que serão processados os dados para os turistas.

As principais funções do Posto de Orientação Virtual são as seguintes:

a) Proporcionar informação e orientação sobre os recursos turísticos: monumentos, museus, entre outros, com conteúdos, horários e preços de entrada;

b) Prestar informações e orientação sobre atividades turísticas: culturais, recreativas, esportivas e de entretenimento.

c) Dar informações e orientação sobre ofertas turísticas com serviços, horários e preços: transporte, hospedagem, restauração, agencias de viagens, agências de aluguel de automóveis, etc;

d) Proporcionar informações sobre dados e endereços de serviços de interesse: consulados, hospitais, órgãos públicos, restaurantes, atendimentos médicos e delegacias, etc;

e) Fornecer material informativo e de propaganda gratuito ou pago, dos tópicos anteriores: folhetos, cartazes, livros, etc;

f) Apresentar dados informatizados por meio de serviços de videotexto, conectados a bancos e base de dados, assim como as centrais de reservas. 
As fontes de informação turísticas para realização do serviço devem basear-se nos seguintes pontos:

1. Fontes manuais e mecanizadas de empresas, instituições e organizações turísticas, tanto internas como externas.

2. Fontes manuais e mecanizadas dos recursos e oferta turísticas, tanto, internas e externas.

3. O processo documental como fontes para o serviço informativo.

4. Analise da informação e seu processo de classificação, catalogação e arquivo de forma manual, mecanizada ou informatizada. Atualização da informação por meio dos bancos de dados e base de dados.

5. Os sistemas integrados de reservas.

\subsection{Localização do Posto:}

Prevê-se, inicialmente, a localização de Postos de Orientação Virtual no aeroporto de Brasília e nos principais hotéis da cidade.

No aeroporto de Brasília, haverá vários postos, situados nos locais mais movimentados. Para o acesso às informações o turista terá que fornecer o seu nome completo, CPF, endereço e o número de telefone. O turista, então, poderá planejar o seu roteiro acessando as principais informações sobre hospedagem, restaurantes, agências de turismo, companhias aéreas e transportes. Selecionadas as informações, o terminal fornecerá uma senha e um mapa contendo as informações escolhidas. 
A proposta é colocar 15 Postos nos principais pontos do aeroporto, que contam com maior afluxo de passageiros, dando-se prioridade aos localizados nas chegadas dos vôos nacionais. Pode-se colocar postos no setor de coleta de bagagem., tanto dos vôos internos quanto internacionais.

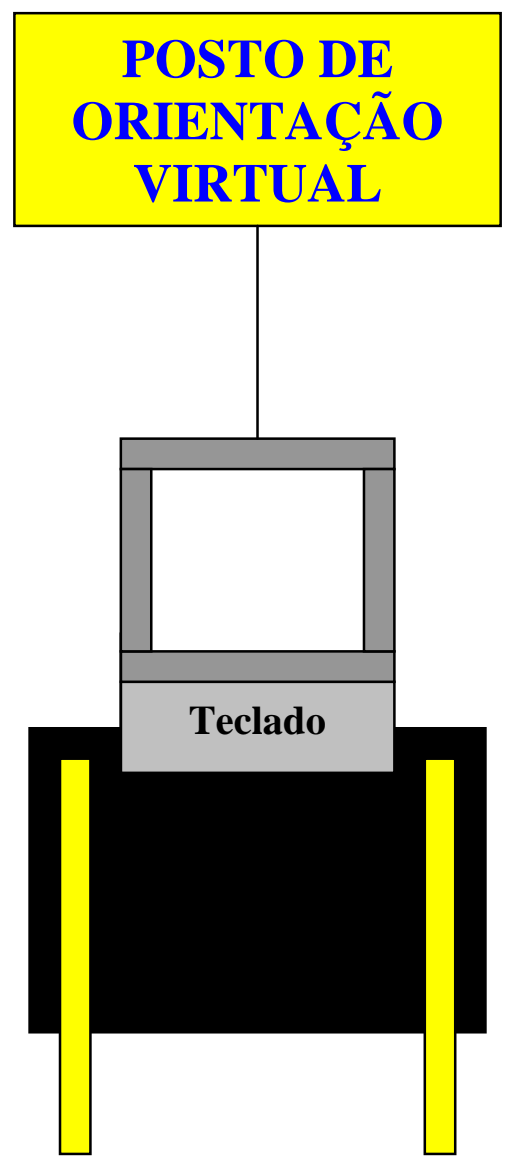




\subsection{Como o turista acessará as informações?}

No vídeo terá um mapa de Brasília e as principais informações a serem acessadas. As informações serão divididas em duas categorias. Na primeira categoria, onde não haverá cobrança de nenhuma taxa, constarão as informações básicas. Nas informações básicas serão abordados a história de Brasília e seus principais pontos turísticos. Já nas informações especificas constarão às informações conforme o objetivo pretendido pelo turista e suas áreas de interesse. Haverá um custo para o acesso às informações nessa categoria, da ordem de 2.50 reais, a serem debitados na conta telefônica do turista. Com esse pagamento, o turista terá direito de acesso a todo Posto de Orientação Virtual em outros lugares, durante toda a duração de sua estadia na cidade.

Para que o turista possa acessar as informações especificas, deverá formulário com seus dados pessoais, incluindo, entre outros, o nome completo, endereço, CPF e o número de telefone residencial, comercial ou celular. O sistema verificará a autenticidade dos números de telefone fornecidos, para que não haja o problema de não ser o titular da conta telefônica.

\subsection{Qual é a função do roteiro:}

No roteiro constarão as informações escolhidas pelo turista. A função principal do roteiro é orientar o turista nos locais escolhidos por ele. No momento que o turista entrar com seus dados, aceitar o serviço de orientação virtual, e responder um questionário contendo as principais informações sobre a sua vista em Brasília, o sistema elabora o roteiro com base nos dados respondidos em questionário. 


\subsection{0 que constará no questionário:}

No questionário constarão as principais perguntas para a formação do roteiro, que, a título ilustrativo e sem qualquer preocupação de ser exaustivo, poderiam ser as seguintes:

1) É a primeira vez em Brasília:

- $\operatorname{Sim}$;

- Não.

2) Quanto dia prende hospedar na cidade:

- Uma noite;

- Uma a duas noites;

- Três para mais.

3) O Senhor (a) veio a negócio:

- Sim.

- Não.

4) O Senhor (a) tem preferência de categoria e conforto de hospedagem;

- Sim.

- Não.

5) O senhor calcula gastar quanto em diárias:

- 50,00 reais

- 51,00 a 100 reais

- 101,00 a 150,00 reais

- 150,00 a 200,00 reais 
6) O Senhor gostaria de um serviço de transporte a sua disposição:

- $\operatorname{Sim}$

- Não

7) Qual é o lugar que irá resolver o seu negócio:

- Esplanada dos Ministérios;

- Setor Bancário Sul

- Setor Bancário Norte

- Outras localidades.

8) Tem alguma preferência de restaurante:

- Sim.

- Não.

As perguntas têm como objetivo analisar o perfil de cada turista que visita Brasília. Esses dados ficaram armazenados e toda vez que o cliente quiser mudar o seu roteiro será gravado e posto no seu arquivo contendo o seu nome a data que foi acessada a primeira vez e as suas devidas mudanças.

No ponto estratégico, as informações fornecidas pela estatística ficam nas mãos dos empreendedores quanto for em sentido de analisar o perfil do turista que vem se hospedar em Brasília. Esse armazenamento de ponto de vista estratégico torna-se um poderoso produto lucrativo em suas mãos. Pois na medida que os turistas utilizem esses serviços gera-se um ciclo de lucratividade. Além de o hotel ganhar, o restaurante e outros serviços do 
interesse dos turistas estão lucrando também. Isso gera emprego e participação da população em mostrar que Brasília é uma cidade que oferece para os turistas de negócios opções e qualidade nos serviços.

\subsection{Fornecimento da Senha para acessar as informações:}

Depois de serem respondidas as perguntas, o turista receberá uma senha que permitirá seu acesso em qualquer POV. A senha terá validade de acordo com a sua estadia em Brasília. O turista não precisará do cartão magnético, pois a senha terá a mesma função que os postos situados nos hotéis.

\subsection{O posto localizado no Hotel:}

Durante a entrada do turista no hotel, a recepção do hotel oferecerá cartão magnético pelo qual poderá acessar as informações desejadas em terminal que deverá estar estrategicamente localizado no hall. O ideal seria que houve um POV em cada andar do hotel.

Com o cartão, o turista poderá formular um roteiro de acordo com seu objetivo. As informações presentes nos postos situados nos hotéis serão as mesmas disponíveis nos terminais situados no aeroporto de Brasília. A diferença é a possibilidade de acesso por meio do cartão magnético, que terá a mesma função da senha.

\subsection{Vantagens para o turista:}

A grande vantagem dos Postos de Orientação Virtual situados no aeroporto e nos hotéis de Brasília é oferecer aos turistas facilidades para acessar as 
principais informações sobre a cidade e seus pontos de interesse. Transforma-se assim em guia de grande utilidade. Em sua chegada no aeroporto, o turista poderá escolher o hotel e fazer as reservas necessárias. Poderá também identificar os restaurante mais próximos do local onde irá realizar o seu trabalho e também optar por um serviço de transporte personalizado.

\section{Posto de Orientação Virtual: Segunda etapa de implementação}

Na segunda parte do processo será analisados a função da central e os benefícios que o Posto de Orientação Virtual oferece para os turistas.

Nos Postos de Orientação Virtual o atendimento é individualizado. O cliente poderá usufruir informações mais especificas de acordo com seu interesse. A participação do hotel é essencial em dois pontos: a eficiência no atendimento e a sua participação no momento que cliente precisa das informações.

Por que a eficiência no atendimento? O objetivo do Posto de Orientação Virtual é orientar os hospedes oferecendo serviços que podem ajudar na sua estadia na cidade. Esse serviço é ativado na medida que o cliente acessa e pede um roteiro.

\subsection{Como serão oferecidos os dados para o turista:}

Depois de responder o questionário o turista poderá escolher dez opções de acordo com seu pedido. Se seu pedido for restaurante, serão oferecidas dez opções mais próximas do local que irá realizar as suas atividades. Os preços dos pratos estarão anexados a cada item (restaurantes). 
Nos restaurantes específicos (por exemplo: restaurantes italianos, portugueses, chineses, etc.). Se a opção for por esse tipo de restaurante será fornecidos o prato e o preço. O turista poderá escolher o prato, a bebida, etc.

Nos restaurantes por "kilo" serão oferecidos os preços do "kilo" e lista de dez restaurantes mais próximos do local do trabalho.

No transporte o turista poderá escolher a característica do veículo de acordo com a sua necessidade. O turista responderá cinco perguntas relacionadas ao seu destino. De acordo com o questionário será passado o preço de cada trecho percorrido.

Se o turista for percorrer, por exemplo, três lugares diferentes (Ministério da Educação, setor bancário sul, PIER 21 para almoço, retorno ao Ministério e ao hotel, o sistema calculará os preços de corrida de taxi de cada trecho com a kilometragem certa).

\subsection{Como serão cadastrados os estabelecimentos:}

Inicialmente será feita uma análise de todos os hotéis, restaurantes, bancos e locais de lazer em Brasília. Serão visitados principalmente os hotéis e restaurantes, onde serão analisados o atendimento e a qualidade do ambiente.

Nos hotéis serão verificados o preço da diária e sua categoria. Serão divididos por categoria de um até cinco estrelas, conforme o ambiente, atendimento e infra-estrutura. Pode-se utilizar a classificação oficial da Embratur.

Nos restaurantes serão verificados os preços de cada prato a qualidade da comida e do atendimento. 
A classificação das informações obedecerá a critério regional, conforme as principais divisões da cidade (Asa Sul, Asa Norte, Lago Sul, Lago Norte, etc.)

Os restaurantes receberá classificação de 1 a 3. A nota que corresponde a 1 indica que são regulares tanto o ambiente quanto a qualidade do atendimento e a variedade do cardápio. Nessa categoria, o preço a ser gasto estaria em torno de 10 até 30 reais. Classificação C

Para a nota que corresponde a 2 , seriam considerados satisfatórios 0 ambiente, a qualidade do atendimento, a variedade do cardápio. O gasto por pessoal variaria entre 30 até 60 reais. Classificação $B$.

Para nota que corresponde a 3 , seriam muito bons ou excelentes 0 ambiente, a qualidade do atendimento e do cardápio. O preço gasto por pessoal se situaria acima de 60 reais. Classificação ${ }^{a}$

Os restaurantes a kilo teriam também uma avaliação em termos de qualidade do comida e do atendimento dos restaurantes de pratos típicos que serão avaliados por categoria de A até C, mas o preço será dado por kilo.

A partir dessas informações serão escolhidos os restaurantes que oferecem qualidade no atendimento e no ambiente de acordo com sua categoria.

Nas tabelas abaixo serão mostrados dois exemplos de tabela de restaurante de prato típico e restaurante Self Service:

\begin{tabular}{|l|l|l|l|l|}
\hline Nome & Região & Categoria & Nota & Preço mínimo por \\
do restaurante & De A até C & De 1 a 3 & pessoa. \\
\hline Restaurante 'X' & Asa Sul & A & 1 & 65,00 reais \\
\hline Restaurante 'Y' & Asa Norte & B & 2 & 55,00 reais \\
\hline
\end{tabular}




\begin{tabular}{|l|l|l|l|l|}
\hline Restaurante 'W' & Asa Norte & C & 3 & 25,00 reais \\
\hline
\end{tabular}

Nos restaurante a KILO será mostrada a tabela abaixo:

\begin{tabular}{|c|c|c|c|c|}
\hline $\begin{array}{l}\text { Nome } \\
\text { do restaurante }\end{array}$ & Região & $\begin{array}{l}\text { Categoria } \\
\text { De A até C }\end{array}$ & $\begin{array}{l}\text { Nota } \\
\text { de } 1 \text { a } 3\end{array}$ & $\begin{array}{l}\text { O preço gasto por } \\
\text { kilo a partir }\end{array}$ \\
\hline Restaurante ' $F$ ' & Asa Norte & $A$ & 1 & 22,90 reais \\
\hline Restaurante 'G' & Asa Norte & $B$ & 2 & 16,90 reais \\
\hline Restaurante 'H' & Asa Sul & $\mathrm{C}$ & 3 & 10,90 reais \\
\hline
\end{tabular}

Serão mostrados fotos de cada restaurante e um resumo de sua historia. Bares e boates serão igualmente avaliados sob critérios uniformes.

\subsection{Qual é a função da central?}

A central tem duas funções. A primeira é formular os pedidos através do roteiro e a Segunda, comunicar com os restaurantes e os transportes repassar a confirmação pelo relatório.

No momento que o turista aciona o serviço a central terá que processar e coletar as informações referentes aos pedidos. Além de formular o roteiro terá que comunicar com o restaurante escolhido e com o transporte. Terá que enviar a confirmação do roteiro para o turista por dois caminhos: o primeiro o roteiro poderá se enviado para o hotel ou ele será ser impresso no local.

Confirmado, o turista receberá no seu quarto o roteiro. O roteiro constará de duas folhas. Na primeira folha será apresentados um esboço do mapa da cidade 
com os lugares selecionados por ele. Na segunda folha, estará um relatório de todos os passos percorridos, contendo a hora, os lugares e a kilometragem percorrida. Abaixo da folha estarão os gastos referentes à alimentação e ao transporte.

No relatório constará em relação ao transporte o tipo de carro e o horário combinado e o preço referente a cada trecho percorrido. No restaurante constará o nome, o local, a categoria e o valor do prato ou do kilo.

A central comunicará o restaurante escolhido dando o horário e o nome do turista e o prato escolhido por ele. Para o transporte a central comunicará com as associações dos táxis para passar o roteiro com todos os trechos que o turista percorrerá.

O turista de negocio não se sentirá perdido, pois a função do roteiro é oferecer um serviço diferenciado com qualidade e deixar o turista sem se preocupar com os detalhes e sim ligado ao seu negocio. Negócio e lazer se juntarão para dar uma à cidade uma nova imagem de hospitalidade. 


\section{Conclusão:}

Nas últimas décadas, o desenvolvimento do turismo teve um rápido crescimento, apresentando-se como um setor economicamente viável.

O turismo é um dos setores mais significativos e dinâmicos do mundo atual. Algumas tendências vêm se delineando, como deslocamentos mais curtos, com maior freqüências e em menor intervalo de tempo. A Organização Mundial de Turismo (OMT) estima um crescimento de 4 a 5 por cento ao ano da área de turismo até o inicio do séculos XXI. Esse crescimento é causado, principalmente, pelo interesse por produtos turísticos novos e renovados, tais como o turismo rural, de aventura e ecológico. Os estudos realizados pela OMT basearam-se na evolução das variáveis de mercado (demanda, oferta de atrativos naturais e culturais, equipamentos turísticos e infra-estrutura) e em variáveis exógenas (demográficas, sociais, econômicas, políticas e legislativas).

A informática é uma ferramenta necessária para o profissional de turismo. Atualmente ela está presente em muitas atividades cotidianas, e não poderia deixar de estar no setor de turismo, onde facilita significativamente atividades como planejamento e desenvolvimento turísticos, hotelaria e agências de viagens.

A informática garante um melhor controle sobre os projetos turísticos, facilita o planejamento eficiente dos serviços e permite maior controle da administração de projetos e a aplicação criteriosa de recursos, com o uso de apoio gráfico, cálculos e relatórios. E, para o gerenciamento de informação no setor de turismo, a informática é uma ferramenta de apoio, facilitando a reflexão critica e a visão sistêmica e valorizando o elemento humano. 
A evolução tecnológica permite que computadores armazenem e manipulem não apenas dados, no sentido tradicional do termo, mas também informações em forma de textos (não-estruturadas, na forma de campos e registros), gráficos, sons e imagens digitais.

O ambiente empresarial está mudando continuamente, tornando-se mais complexo e menos previsível, e cada vez mais dependentes de informação e de toda a infra-estrutura tecnológica que permite o gerenciamento de enormes quantidades de dados. A tecnologia está gerando grandes transformações, que estão ocorrendo a nossa volta de forma ágil e sutil. É uma variação com conseqüências fundamentais para o mundo empresarial, causando preocupação diária aos empresários e executivos das corporações, com o estágio do desenvolvimento tecnológico das empresas e/ou de seus processos internos. A convergência desta infra-estrutura tecnológica com as telecomunicações que aniquilou as distâncias está determinando um novo perfil de produtos e de serviços.

O principal benefício que a tecnologia da informação traz para as organizações é a sua capacidade de melhorar a qualidade e a disponibilidade de informações e conhecimentos importantes para a empresa, seus clientes e fornecedores. Os sistemas de informação mais modernos oferecem às empresas oportunidades sem precedentes para a melhoria dos processos internos e dos serviços prestados ao consumidor final".

Neste contexto, os Postos de Orientação Virtual do turista, que constituem a proposta do presente trabalho, poderão se constituir em ferramenta muito útil para o desenvolvimento do turismo em Brasília. O turismo de negócio é o principal tipo 
de turismo na capital federal. Trata-se de público exigente, com interesses específicos e que necessita receber um serviço rápido, de fácil acesso e com qualidade.

Essas características podem ser encontradas nos serviços disponíveis nos POV, que estarão localizados estrategicamente no aeroporto e nos grandes hotéis. A estada do turista de negócios, principalmente, movimenta a economia da cidade. A orientação precisa e eficiente desse pessoal acarretarão benefícios positivos em termos econômicos e sociais. A utilização da tecnologia de informação, por sua vez, torna possível a realização da proposta. Com ela, Brasília teria muito a ganhar em termos de imagem de cidade preocupada em fornecer bons serviços aos seus visitantes. 
BIBLIOGRAFIA CONSULTADA:

1. BILL GATES - A Estrada do Futuro. São Paulo: Makron Books do Brasil, 2001

2. CHARLES B. WANG - Tecno Vision II . São Paulo: Makron Books do Brasil,1999

3. FERNANDES, Jorge Monteiro - Gestão da Tecnologia com parte Estratégica competitiva das Empresas - Copyright, 2003.

4. Manual de Tecnologia da Informação - Adriana Beal.

5. MARQUES, MARIA ANGELA - Planejamento Turístico Municipal com Suporte em sistema de informação - Ed. Futura - São Paulo, 2001.

6. MONTEJANO, JORDI MONTANER - Estrutura do Mercado Turístico Ed. Roca - São Paulo, 2001.

7. POLLONI, Errico G. F. - Administrando Sistemas de Informação - Ed. Futura,2000.

8. SANTOS, R. N. M. Sistemas de informação estratégica para viabilidade da empresa. Ciência da Informação, n.1, v.25, jan/abr de 1996.

9. TASPCOTT, D. CASTON, A mudança de paradigma: a nova promessa da tecnologia de informação. São Paulo: Makron Books do Brasil, 1995. 
10.Tecnologia da Informação e Estratégia Empresarial de Jacques Marcovith.

11. Revista Gestão Empresarial.

12. Revista Brasília Convention \& Visitors Bureau - 2000.

13. VELOSO, Marcelo Parreira - Turismo simples e eficiente - Ed. Roca São Paulo, 2003. 
